\title{
The adapter protein Myd88 plays an important role in limiting mycobacterial growth in a zebrafish model for tuberculosis
}

\author{
Rohola Hosseini ${ }^{1} \cdot$ Gerda E. M. Lamers ${ }^{1} \cdot$ Erik Bos $^{2} \cdot$ Pancras C. W. Hogendoorn ${ }^{3}$ (D) Abraham J. Koster ${ }^{2}$. \\ Annemarie H. Meijer ${ }^{1} \cdot$ Herman P. Spaink ${ }^{1}$ - Marcel J. M. Schaaf ${ }^{1}$
}

Received: 24 June 2020 / Revised: 19 January 2021 / Accepted: 22 January 2021 / Published online: 9 February 2021

(C) The Author(s) 2021

\begin{abstract}
Tuberculosis (TB) is the most prevalent bacterial infectious disease in the world, caused by the pathogen Mycobacterium tuberculosis (Mtb). In this study, we have used Mycobacterium marinum $(\mathrm{Mm})$ infection in zebrafish larvae as an animal model for this disease to study the role of the myeloid differentiation factor 88 (Myd88), the key adapter protein of Toll-like receptors. Previously, Myd88 has been shown to enhance innate immune responses against bacterial infections, and in the present study, we have investigated the effect of Myd88 deficiency on the granuloma morphology and the intracellular distribution of bacteria during $\mathrm{Mm}$ infection. Our results show that granulomas formed in the tail fin from myd88 mutant larvae have a more compact structure and contain a reduced number of leukocytes compared to the granulomas observed in wild-type larvae. These morphological differences were associated with an increased bacterial burden in the myd88 mutant. Electron microscopy analysis showed that the majority of $\mathrm{Mm}$ in the myd88 mutant are located extracellularly, whereas in the wild type, most bacteria were intracellular. In the myd88 mutant, intracellular bacteria were mainly present in compartments that were not electron-dense, suggesting that these compartments had not undergone fusion with a lysosome. In contrast, approximately half of the intracellular bacteria in wild-type larvae were found in electron-dense compartments. These observations in a zebrafish model for tuberculosis suggest a role for Myd88-dependent signalling in two important phenomena that limit mycobacterial growth in the infected tissue. It reduces the number of leukocytes at the site of infection and the acidification of bacteria-containing compartments inside these cells.
\end{abstract}

Keywords Zebrafish · Tail fin · Infection · Mycobacterium · Tuberculosis · Macrophage $\cdot$ Leukocyte dynamics · Efferocytosis · Cell death

\section{Introduction}

Pulmonary tuberculosis (TB) is an often-lethal bacterial infection caused by Mycobacterium tuberculosis (Mtb), which is estimated to have infected one-third of the global population. Currently, over a million people die as a consequence of this infection annually [1]. Increasing occurrence of multi-drugresistant $M t b$ strains is widespread, and in order to develop

Pancras C. W. Hogendoorn p.c.w.hogendoorn@lumc.nl

1 Institute of Biology Leiden, Leiden University, Leiden, Netherlands

2 Department of Cell and Chemical Biology, Leiden University Medical Center, Leiden, Netherlands

3 Department of Pathology, Leiden University Medical Center, Albinusdreef 2, 2333 Leiden, ZA, Netherlands novel therapeutic strategies, a better understanding of tuberculosis is required $[2,3]$.

During the pathogenesis of TB, Mtb displays a complex interaction with the immune system of the host. Mtb is phagocytized by macrophages, in which it prevents acidification and degradation of the phagosomal content $[4,5]$. In addition, there is evidence that $M t b$ is able to escape from the phagosomes into the cytoplasm of the macrophage $[6,7]$. In these infected cells, the $M t b$ bacteria create a niche, in which they can survive for long periods of time and replicate $[8,9]$. Pro-inflammatory signals from infected macrophages initiate the recruitment of other innate and adaptive immune cells to the primary infection site, leading to the formation of highly organized granulomatous lesions. In these granulomas, $M t b$ can persist for many years, forming a latent infection by minimizing its metabolic and replicative activity. However, $M t b$ can also be reactivated resulting in an active TB infection [10]. 
Despite the fact that $M t b$ exploits macrophages to persist inside its host, this cell type is indispensable for the host in order to keep Mtb infection under control. Macrophages recognize invading pathogens at the first stage of infection and initiate an immune response. Recognition of pathogenassociated molecular patterns (PAMPs) and endogenous danger-associated molecular patterns (DAMPs) occurs through pattern recognition receptors (PRRs), of which the Toll-like receptors (TLR) are one of the major classes [11, 12]. Myeloid differentiation factor 88 (MYD88) is a key adaptor protein in the TLR signalling pathway since it is used by all TLRs (except for TLR3) to initiate an inflammatory response [13]. The C-terminal TIR domain of MYD88 enables interaction with TLRs or the interleukin-1 receptor (IL1R), and the $\mathrm{N}$-terminal death domain enables the formation of a "Myddosome" signalling complex, consisting of IL-1 receptor associated kinases (IRAKs). The Myddosome plays a central role in inflammation and host defence by activating the mitogen-activated protein kinase (MAPK) signalling pathway and the nuclear factor-kB (NF-kB) transcription factor complex [14-17]. MyD88-deficient mice show increased susceptibility to various pathogens, among them $M t b$ [18].

Zebrafish are naturally susceptible to mycobacterial infection, caused by Mycobacterium marinum ( $\mathrm{Mm})$, which is genetically closely related to $M t b . M m$ induces a similar pathology to its human equivalent, including the formation of tuberculous granulomas [19,20]. The larval stage of the zebrafish enables detailed in vivo imaging and has been used extensively to study host-pathogen interactions during $M m$ infection [19, 21-23]. In zebrafish larvae, infected macrophages and neutrophils aggregate and form initial granulomas, which makes this model highly suitable to study the role of innate immune cells during the progression of mycobacterial infection [24]. The observed granulomas at larval stage appear to be highly dynamic in nature, characterized by the active recruitment of macrophages during early $\mathrm{Mm}$ infection and the reverse migration of infected macrophages from infected sites [25].

In previous work, we have shown that the Myd88signalling pathway has a protective role during $\mathrm{Mm}$ infection in zebrafish larvae [26-29]. Larvae from a myd88 mutant line $\left(m y d 88^{-/}\right)$or $m y d 88$ knockdown larvae showed decreased induction of pro-inflammatory cytokines $[28,30]$, lower production of reactive nitrogen species by neutrophils [26] and attenuated initiation of autophagic defence [27], resulting in increased rates of infection.

In the present study, we have used the $m y d 88^{-/}$line to study the effect of Myd88 deficiency on granuloma morphology and subcellular localization of $\mathrm{Mm}$ infection. To this end, we used our previously described tail fin injection model [24, 31], in which the formation of a single granuloma can be monitored over time and imaged by a combination of confocal and electron microscopy. Our results show that $\mathrm{Mm}$ infection in myd 88 mutant larvae results in an increased bacterial burden associated with strongly reduced recruitment of leukocytes to granulomas. The majority of $\mathrm{Mm}$ was found to be located extracellularly in myd88 mutants, and bacteria that were found inside cells were mostly observed as aggregates in compartments that were not acidified. These data indicate a specific role for Myd88-dependent signalling in the protection against $M m$ infection.

\section{Materials and methods}

\section{Zebrafish strains and maintenance}

Zebrafish were handled in compliance with the local animal welfare regulations and maintained according to standard protocols (www.zfin.org). Wild-type and the myd88 $8^{\text {hu3568 }} z$ ebrafish strains were used for this study, and culturing the myd $88^{\text {hu3 } 368}$ strain was approved by the local animal welfare committee (DEC) of the University of Leiden (protocol 12232). All fish were raised and grown at $28.5^{\circ} \mathrm{C}$ on a 14 -h light:10-h dark cycle. Embryos were obtained from natural spawning at the beginning of the light period and kept in egg water $(60 \mu \mathrm{g} / \mathrm{ml}$ Instant Ocean sea salts).

\section{Zebrafish tail fin infection}

The M. marinum $\mathrm{M}$ strain fluorescently labelled with E2crimson was used and prepared at $\sim 50$ colony-forming units per $1 \mathrm{nl}$ as previously described [32]. Borosilicate glass microcapillaries (Harvard Apparatus, USA) were used with a micropipette puller device (Sutter Instruments Inc., USA) for preparing microinjection needles. Zebrafish larvae were injected in the tail fin at $3 \mathrm{dpf}$ using the Eppendorf microinjection system with a fine ( $\sim 5$ to 10 micron) needle tip broken off with tweezers and mounted at a 30-degree angle. Larvae were anesthetized in egg water with $200 \mu \mathrm{g} / \mathrm{mL} 3$ aminobenzoic acid (tricaine; Sigma-Aldrich, USA) and injected between the 2 epidermal layers at the ventral part of the tail fin (Fig. 1), as previously described [31]. Larvae were fixed at desired time points after infection with $4 \%$ paraformaldehyde in PBS-T (phosphate-buffered saline; $\mathrm{NaCl} 150$ $\mathrm{mM}, \mathrm{K}_{2} \mathrm{HPO}_{4} 15 \mathrm{mM}, \mathrm{KH}_{2} \mathrm{PO}_{4} 5 \mathrm{mM}$ ) with $0.05 \%$ Tween 20 (Merck Millipore, Germany) with gentle agitation for $18 \mathrm{~h}$ at $4{ }^{\circ} \mathrm{C}$. The larvae were washed the next day with PBS-T and stored at $4{ }^{\circ} \mathrm{C}$ for further staining or until imaging.

\section{Lcp1 immunohistochemistry}

For Lcp1 immunostaining, larvae were anesthetized with $200 \mu \mathrm{g} / \mathrm{ml}$ tricaine and then immediately fixated in $4 \%$ paraformaldehyde in PBS (phosphate-buffered saline, $\mathrm{pH}$ 7.2) for $16 \mathrm{~h}$ at $4{ }^{\circ} \mathrm{C}$. After fixation, the larvae were rinsed 
a

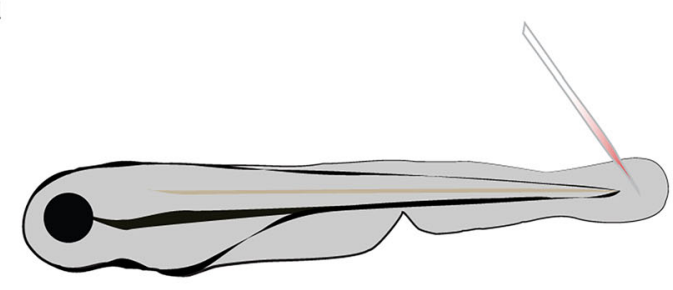

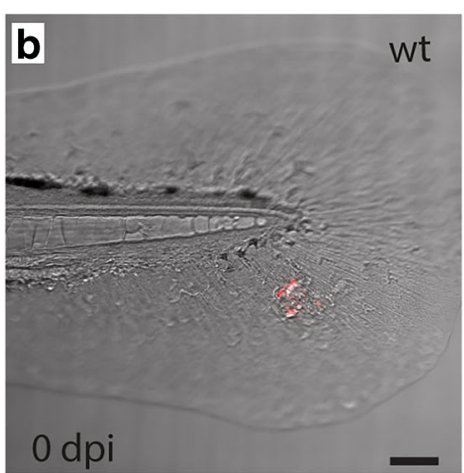

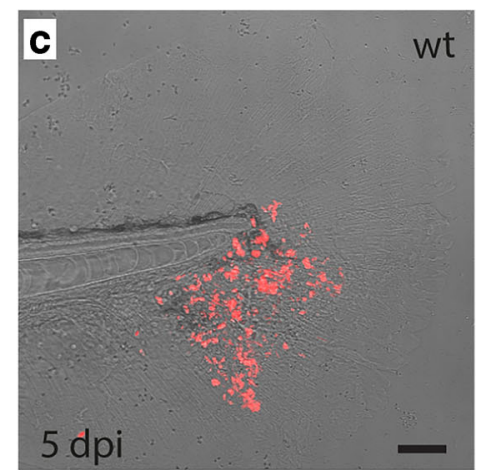

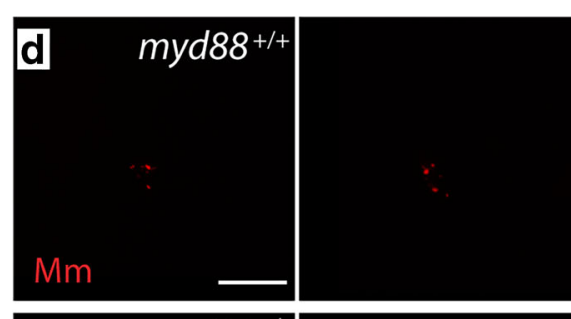
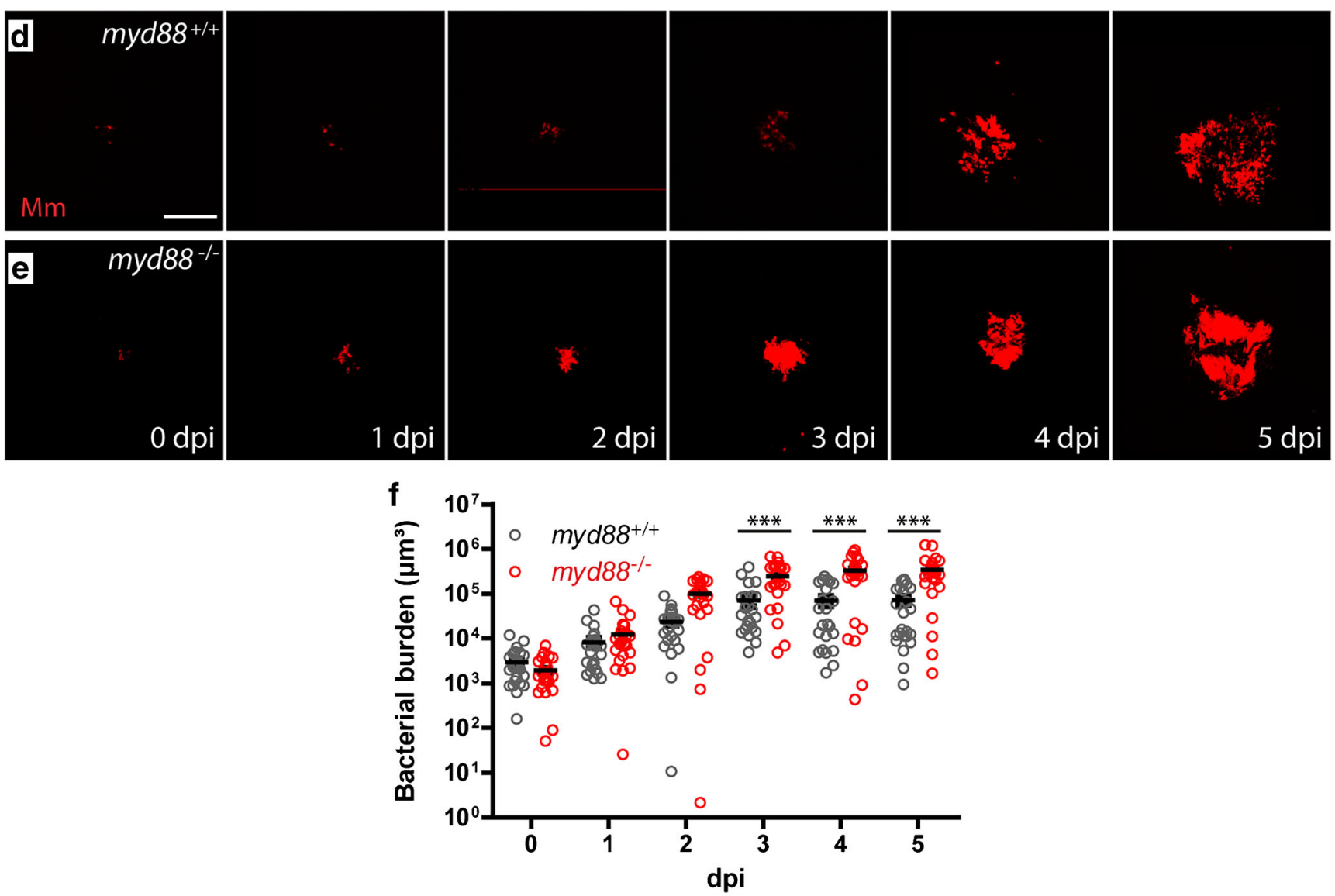

Fig. 1. Granuloma development and morphology in the tail fin of zebrafish larvae. a $\mathrm{Mm}$ injection in the tail fin generates single granuloma. b,c Infected tail fin of the same larva with fluorescently labelled $\mathrm{Mm}$ (red) at $4 \mathrm{~h}$ post infection (b) and at 4 days post infection (c) showing the localized development of the early granuloma structures. d,e Representative images of larvae showing the increase of $\mathrm{Mm}$ infection (red) and development of granuloma structures in the wild type (d) and $m y d 88^{-/-}$larvae (e). f Bacterial burden in the $m y d 88^{+/+}$(black) and myd $88^{-/-}$(red) larvae. The data (mean \pm SEM) were analysed using analysis of variance (ANOVA); Bonferroni's multi comparison posttest was performed on myd88 wild type and mutant larvae at each time point $(* * * p<0.0001, n>20$ larvae per time point). The scale bars represent $100 \mu \mathrm{m}$ in PBS-DTx (phosphate-buffered saline with 0.5\% DMSO and $0.3 \%$ Triton $\mathrm{X}-100)$ and treated with proteinase $\mathrm{K}(10$ $\mu \mathrm{g} / \mathrm{ml}$ in PBS-DTx; Roche) for $10 \mathrm{~min}$ at $37^{\circ} \mathrm{C}$. The larvae were blocked in 5\% normal sheep serum (SigmaAldrich) in PBS-DTx for $2 \mathrm{~h}$ at room temperature, incubated with Lcp1/L-Plastin antibody (a gift from Dr. Anna Huttenlocher, University of Wisconsin, USA) in 1:1000 dilution at $4{ }^{\circ} \mathrm{C}$ overnight and subsequently incubated with Alexa-488 conjugated secondary antibody (1:200; Invitrogen) for $2 \mathrm{~h}$ at room temperature. The 
larvae were washed with PBS-DTx and stored at $4{ }^{\circ} \mathrm{C}$ until imaging.

\section{TUNEL assay}

The TUNEL experiments were performed after fixation (anesthetized with $200 \mu \mathrm{g} / \mathrm{ml}$ tricaine and afterwards immediately fixated in $4 \%$ paraformaldehyde in PBS for $16 \mathrm{~h}$ at $4{ }^{\circ} \mathrm{C}$ ) of larvae using Millipore ApopTag Peroxidase In Situ Apoptosis detection kit and Roche Anti-Digoxigenin-POD Fab fragments using a protocol adapted for use in zebrafish larvae [33]. TSA Fluorescence kits (Perkin Elmer, USA) Fluorescein was used for fluorescence detection.

\section{Confocal laser scanning microscopy}

Larvae were mounted in $1 \%$ low melting agarose (SigmaAldrich, USA) and imaged with a Leica TCS SPE (Wetzlar, Germany) confocal laser scanning microscope (CLSM) using 488 and the 633 laser lines and a 20X (NA 0.7) objective (for the images used in Fig. 1b-e) or a Nikon A1 CLSM (Tokyo, Japan) using 488 and the 641 laser lines and a 20X (NA 0.75) objective (for the images used in Figs. 1f, 2 and 3). Images were analysed using Fiji [34] or NIS-elements 4 (Nikon) software. The images of larvae used in Fig. 1b-e were visually inspected using maximum z-projections, and cropped regions of infection were generated using Fiji software. The bacterial burden was measured as the total volume (in $\mu \mathrm{m}^{3}$ ) of the fluorescent signal of M. marinum in the 3D images (12 bit) in Nis-elements 4 , i.e. the total volume of the voxels with a signal above a certain fluorescence intensity threshold (using the same threshold for all larvae). The numbers of TUNELand Lcp1-positive cells were counted manually for each image.

\section{Transmission electron microscopy}

Before being used for electron microscopy, the zebrafish larvae were anesthetized with $200 \mu \mathrm{g} / \mathrm{ml}$ tricaine and afterwards immediately fixated in $2 \%$ glutaraldehyde and $2 \%$ paraformaldehyde in sodium cacodylate buffer $(\mathrm{pH}$ 7.2) for $3 \mathrm{~h}$ at room temperature followed by fixation for $16 \mathrm{~h}$ at $4{ }^{\circ} \mathrm{C}$. Postfixation was performed in $1 \%$ osmium tetroxide in sodium cacodylate buffer for $1 \mathrm{~h}$ at room temperature. After dehydration through a graded series of ethanol, all specimens were kept in epoxy resin (Agar Scientific, UK) for $16 \mathrm{~h}$ before embedding. Ultra-thin sections were collected on Formvar coated 200 mesh or one-hole copper grids (Agar Scientific, UK) stained with $2 \%$ uranyl acetate in $50 \%$ ethanol and lead citrate for $10 \mathrm{~min}$ each. Electron microscopy images were obtained with a JEM-1010 transmission electron microscope (JEOL, Japan) equipped with an Olympus Megaview camera (Tokyo, Japan). A $200 \mathrm{kV}$ Tecnai 20 FEG transmission electron microscope (FEI Company, the Netherlands) equipped with a $4 \mathrm{k} \times 4 \mathrm{~K} \mathrm{CCD}$ camera (Gatan, USA) was used to image large specimen tissues with the automatic montaging of individual images into large overviews with high resolution [35].

For TEM imaging and a quantitative analysis of the images, three larvae for each group (wild type and mutant) were
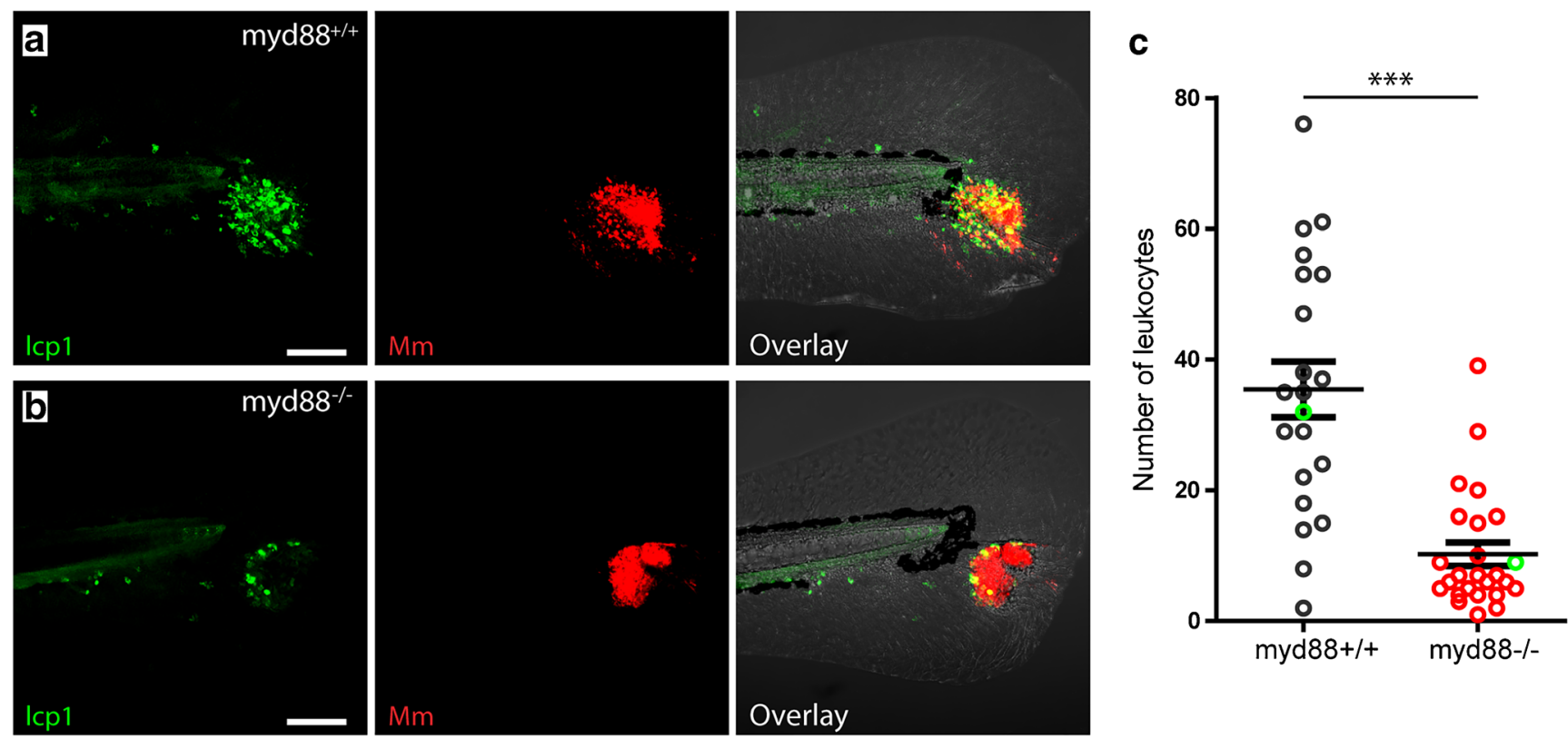

Fig. 2 Number of leukocytes at the site of infection in $m y d 88^{+/+}$and myd $88^{-/-}$larvae. a,b Representative images of a larva showing lcp1positive cells (green) and $M m$ (red) in $m y d 88^{+/+}$(a) and $m y d 88^{-/-}$(b) larvae at 4 dpi. c Quantification of lcp1-positive cell shows less

leukocytes to be present at the site of infection in $m y d 88^{-/-}$larvae. The data (mean $\pm \mathrm{SEM})$ were analysed using a two-tailed student $t$ test $(* * * p$ $<0.001, n>20$ larvae per condition). Scale bar represents $100 \mu \mathrm{m}$ 

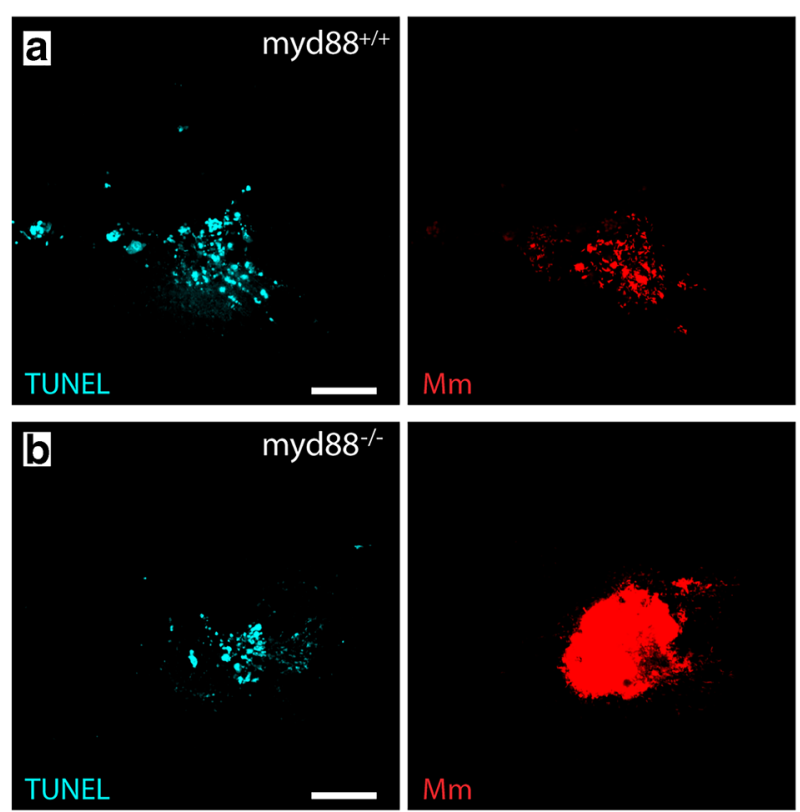

Fig. 3 TUNEL-positive cells at the site of infection in $m y d 88^{+/+}$and myd $88^{-/-}$larvae. a,b Representative images of a larva showing TUNELpositive cells (green) and $\mathrm{Mm}$ (red) in $m y d 88^{+/+}$(a) and $m y d 88^{-/-}$(b) larvae at 4 dpi. c Quantification of TUNEL-positive cell shows fewer

used, and a section in the middle of the initial granulomas was imaged. Quantification was done by manually counting and classifying individual bacteria. The total number of bacteria counted for this analysis was 2178 and 1655 , for wild type and mutant, respectively.

\section{Statistical analysis}

All data (mean \pm SEM) were analysed using Prism version 5.0 (GraphPad Software) using one-way analysis of variance (ANOVA) with Bonferroni's multi comparison post-test for multiple groups. Two-tailed Student $t$ tests were used for comparing 2 conditions.

\section{Results}

\section{Myd88 deficiency affects granuloma morphology and increases bacterial burden}

We have previously shown that TLR/IL1R-Myd88 signalling is required for defence of zebrafish larvae systemically infected with $M$. marinum $(\mathrm{Mm})$. In the present study, we used a previously established localized infection in the tail fin [31], to investigate the initial granuloma formation and subcellular localization of $\mathrm{Mm}$ at the site of infection. Homozygous myd88 mutant ( $\left.m y d 88^{-/-}\right)$and wild-type larvae (myd $88^{+/+}$) were infected with $\sim 50$ colony-forming units (cfu) of fluorescently labelled $\mathrm{Mm}$ in the tail fin at 3 days
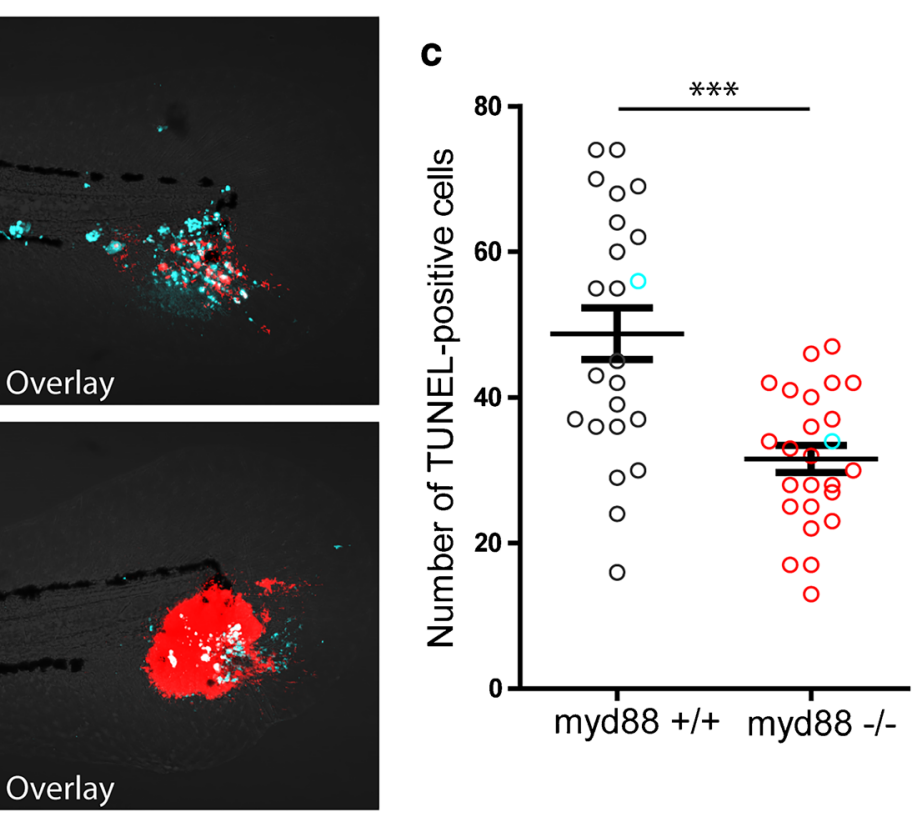

dead cells to be present at the site of infection in $m y d 88^{-/-}$larvae. The data (mean $\pm \mathrm{SEM}$ ) were analysed using a two-tailed student $t$ test ( $* * * p$ $<0.001, n>20$ larvae per condition). Scale bar represents $100 \mu \mathrm{m}$

post fertilization (dpf). The infection in these larvae develops into a granuloma-like structure within 3 to 5 days post infection (dpi).

To provide a detailed description of the infection process and the development of the granuloma structure, confocal laser scanning microscopy (CLSM) was performed on the tail fin of infected myd88 $8^{-/-}$and wild-type $\left(m y d 88^{+/+}\right)$larvae. The bacterial burden in representative $m y d 88^{+/+}$and $m y d 88^{-/-}$larvae is shown in Fig. 1. The infection in each of these larvae was imaged at $4 \mathrm{~h}$ post infection (hpi) and at 1, 2, 3, 4 and 5 dpi. From 2dpi onward we observed compacted bacterial aggregates in $m y d 88^{-/-}$larvae (Fig. 1e), while in the $m y d 88^{+/+}$ larvae, these aggregates were smaller and more widely distributed over the infected tissue (Fig. 1d).

In a separate experiment, the bacterial burden was quantified in the $m y d 88^{+/+}$and $m y d 88^{-/-}$larvae, based on fixed samples at 0 to 5 dpi (Fig. 1F). The bacterial burden was measured as the total volume of the fluorescent signal of $\mathrm{Mm}$. The burden increased significantly between 0 and 3 dpi in the $m y d 88^{+/+}$and the $m y d 88^{-/-}$larvae but increased at a lower rate in the $m y d 88^{+/+}$larvae, compared to the rate in the $m y d 88^{-/-}$larvae, resulting in larger burdens at later time points in the mutant. At 4dpi, the difference in infection level between $m y d 88^{+/+}$and $m y d 88^{-/-}$larvae was maximal with a bacterial volume of $69 \cdot 10^{3}\left( \pm 1.6 \cdot 10^{3}\right) \mu^{3}$ and $328 \cdot 10^{3}\left( \pm 52 \cdot 10^{3}\right) \mu^{3}$, respectively. In line with previous results obtained using a systemic infection model [28], localized $M m$ infection in the tail fin of $m y d 88^{-/-}$larvae results in an increased bacterial burden. 


\section{Reduced number of leukocytes at the infection site in myd88 ${ }^{-/-}$larvae}

In order to investigate the presence of leukocytes at the site of infection in $m y d 88^{-/-}$zebrafish, we performed Lcp1/L-plastin immunostaining at 4 dpi for visualization of all leukocytes (Fig. 2). The larvae were imaged using CLSM, and representative images are shown for $m y d 88^{+/+}$and $m y d 88^{-/-}$larvae (Fig. 2 a and b, respectively). At 4 dpi, the infection in the tail fin has resulted in the formation of an initial stage granuloma, which in $m y d 88^{+/+}$larvae was observed as a large local accumulation of L-plastin-positive cells $(35.4 \pm 4.2)$ at the site of the infection in the tail fin (Fig. 2a and c). In the myd88 $8^{-/-}$ larvae, the number of L-plastin-positive cells at the site of infection was significantly lower (10.2 \pm 1.8$)$.

The lower number of leukocytes observed at the site of

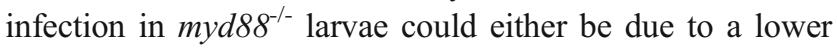
number of leukocytes recruited to the infected area or to a higher rate of cell death of these cells. To address this issue, we performed a fluorescent terminal deoxynucleotidyl transferase dUTP nick end-labelling (TUNEL) assay, which visualizes double-stranded DNA breaks, thereby labelling apoptotic as well as necrotic cells (Fig. 3). At 4 dpi, $m y d 88^{+/+}$larvae show a high number of TUNEL positive cells $(48.7 \pm 3.6)$ throughout the site of infection (Fig. 3a). The $m y d 88^{-/-}$larvae show a lower number of TUNEL positive cells $(31.6 \pm 1.8$; Fig. $3 \mathrm{~b}$ and c). Although alternative explanations such as infection-induced Myd88-dependent changes in haematopoiesis, or leukocyte cell death that is occurring systemically at earlier time points, the observations suggest that the lower number of leukocytes at the infection sites in myd $88^{-/-}$larvae is a consequence of reduced recruitment rather than increased cell death.

\section{Transmission electron microscopy reveals reduced acidification of $\mathrm{Mm}$ containing compartments in myd88 $8^{-/-}$larvae}

In order to analyse effects of Myd88 deficiency at an ultrastructural level, transmission electron microscopy (TEM) was performed on the tail fin granulomas of $\mathrm{Mm}$ infected $m y d 88^{+/+}$ and $m y d 88^{-/-}$larvae (Fig. 4). At $5 \mathrm{dpi}$, the $m y d 88^{+/+}$larvae show a necrotic centre in the infected area, visible as a hole in the tail fin, surrounded by bacteria-containing cells (Fig. 4a and b). In the $m y d 88^{-/-}$larvae, the majority of bacteria were found to reside extracellularly (Fig. $4 \mathrm{c}$ and d), and the area containing extracellular bacteria is surrounded by infected cells (Fig. 4d). Such areas with extracellular bacteria are absent in wild-type larvae.

To determine the nature and frequency of different cellbacterium interactions in $m y d 88^{+/+}$and $m y d 88^{-/-}$larvae, we used a previously described procedure [31], in which we quantified the occurrence of intracellular $\mathrm{Mm}$ in the cytoplasm without any membrane structures surrounding it, or in different types of intracellular compartments, as individual bacteria or as aggregates. The results of this quantification and representative images of each type of interaction are shown in Fig. 5. A large fraction of intracellular bacteria occurred in compartments containing more than 5 bacteria (hereafter referred to as aggregates), both in $m y d 88^{+/+}(\sim 64 \%)$ and in $m y d 88^{-/-}$ larvae $(\sim 50 \%)$ (Fig. 5a and b). However, electron-dense compartments containing these aggregates (hereafter referred to as electron-dense aggregates) were much less abundant in mutant larvae $(\sim 8 \%)$ compared to wild type ( $39 \%$, Fig. 5 b). These compartments are characterized by a uniform electrondense content and probably reflect lysosomes or phagosomes that have been fused with a lysosome. Individual bacteria were present in membrane-engulfed compartments, characterized by a single membrane without any cytoplasmic material, probably reflecting phagosomal structures (Fig. $5 \mathrm{c}$ ). In mutant larvae, those membrane-engulfed compartments were found more often $(\sim 27 \%)$ than in the wild types $(\sim 13 \%)$. Bacteria in the cytoplasm, not enclosed by a membrane, were observed in the type and mutant larvae at a similar frequency, $(\sim 16 \%$ and $\sim 17 \%$ respectively; Fig. 5 d). In addition, bacteria were occasionally found in membrane-engulfed compartments containing cytoplasmic material, in the $m y d 88^{+/+}(\sim 2 \%)$ and $m y d 88^{-/-}$ $(\sim 1 \%)$ larvae. These compartments are characterized by partially degraded cytoplasmic content and organelles, probably as a result of engulfment by or fusion with autophagosomes. This morphology was previously shown to be associated with the localization of the Lc3 protein, using correlative light and electron microscopy, which also suggests an autophagic origin [31] (Fig. 5e). Finally, sometimes bacteria were located inside electron-dense, membrane-engulfed compartments with a regular electron-dense content in the wild-type and myd $88^{-/-}$larvae $(\sim 5 \%$ and $\sim 4 \%$ respectively; Fig. $5 \mathrm{f})$. These electron-dense compartments probably reflect lysosomes with acidic content. In conclusion, the most notable difference between $m y d 88^{-/}$and wild-type larvae was the reduced presence of electron-dense aggregates in the mutant.

\section{Discussion}

In this study, we provide a new insight in the early stages of granuloma development and ultrastructural morphology during $\mathrm{Mm}$ infection in zebrafish larvae using both light and electron microscopy. We show that upon injection of bacteria in the tail fin, a localized infection develops in both $m y d 88^{+/+}$ and $m y d 88^{-/-}$larvae. In the $m y d 88^{-/-}$larvae, the infection developed more rapidly resulting in an increased infection rate at $4 \mathrm{dpi}$. This is consistent with our earlier observations of an increased bacterial burden in $m y d 88^{-/-}$larvae using a blood island infection model [28]. In addition, using the tail fin infection model, we observed a clearly different phenotype of 

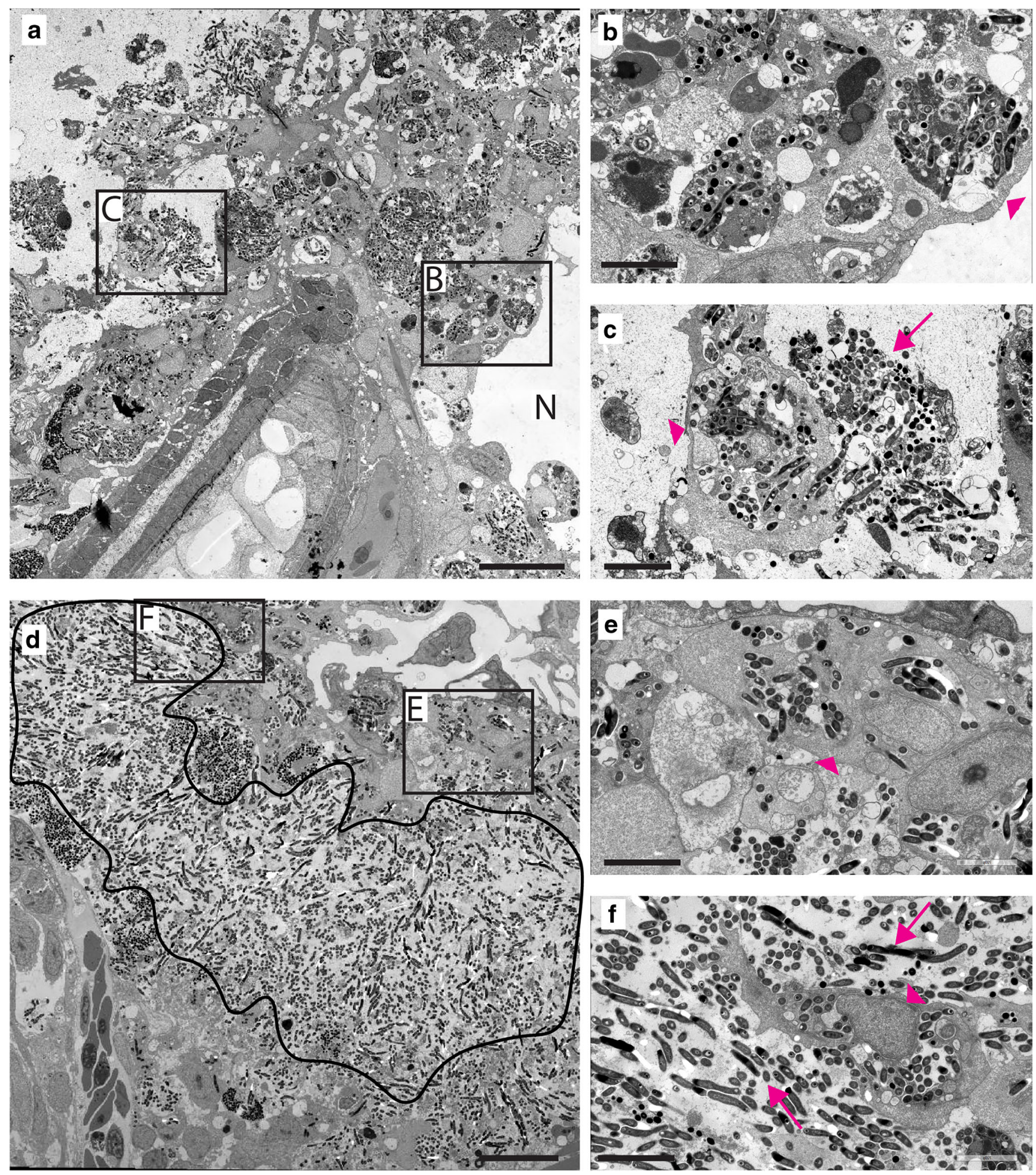

Fig. 4 Granuloma structures in myd88 $8^{-/}$larvae consist mainly of extracellular $\mathrm{Mm}$. a TEM image of a granuloma in representative myd $88^{+/+}$larvae, showing the necrotic centre $(\mathrm{N})$ and aggregates of $\mathrm{Mm}$ in the immune cells. b,c Higher magnification of regions indicated in (a), showing infected cells (arrowheads) and extracellular $\mathrm{Mm}$ (arrows). d

infection in the mutant compared to the wild-type larvae (Fig. $1 \mathrm{~d}$ and e). The results of the present study suggest that the
TEM image of a granuloma in representative $m y d 88^{-/-}$larvae showing the area with extracellular $\mathrm{Mm}$ (black line). e,f Higher magnification of region indicated in (d), showing extracellular bacteria and infected cells (arrowheads). $n=3$ per group, the scale bars in (a)-(d) $(20 \mu \mathrm{m})$ and in (b) $-(\mathbf{c})$ and $(\mathbf{e})-(\mathbf{f})(10 \mu \mathrm{m})$ increased bacterial burden is a result of two compromised host-protective processes: the recruitment of leukocytes that 

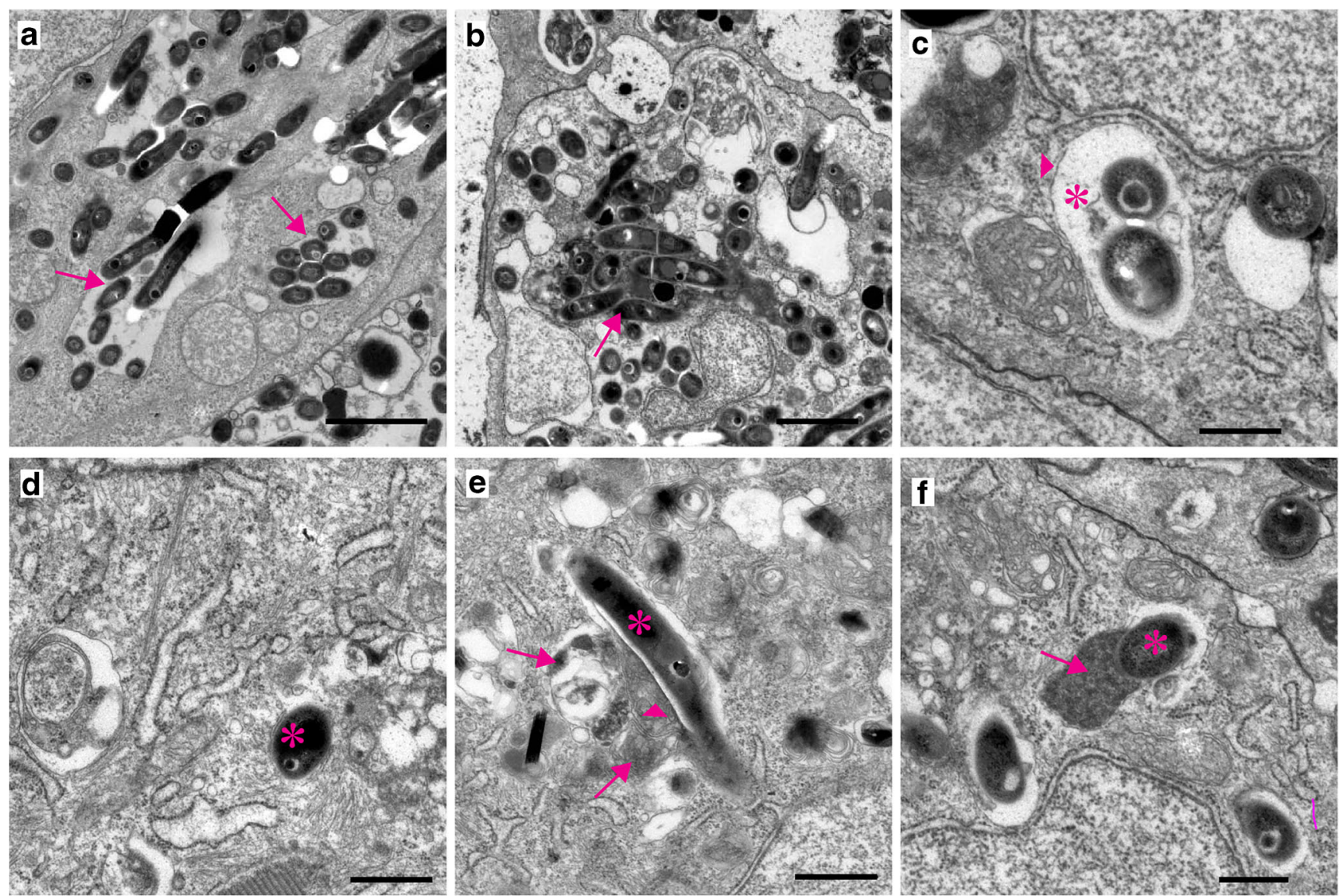

g

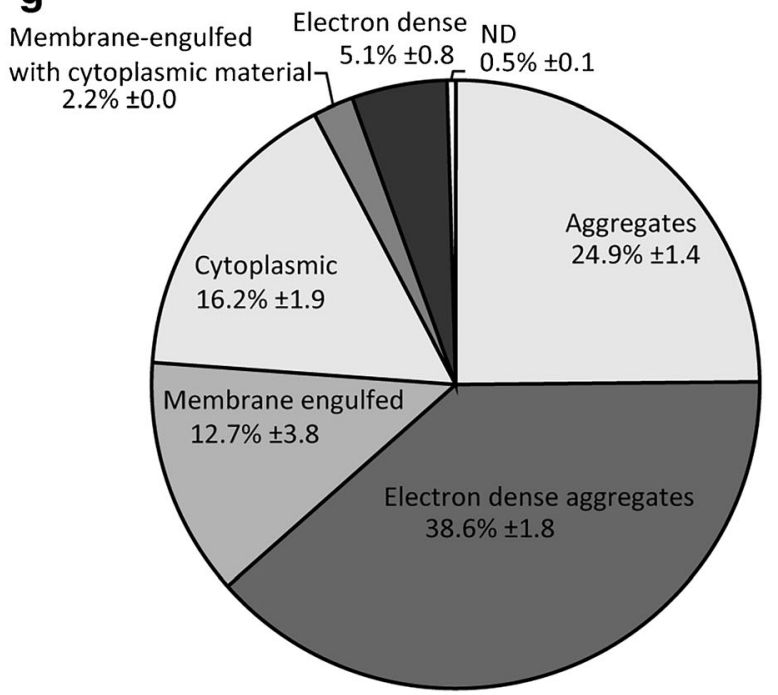

Fig. 5. Quantification of intracellular $M m$ shows altered distribution of

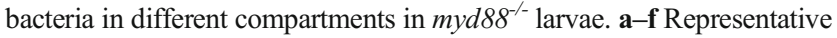
TEM images of $M m$ in different compartments. a Aggregates as a compact cluster of bacteria $(>5)$ without any electron-dense areas (arrows). b Electron-dense aggregates as a compact cluster of bacteria in a compartment having a uniform high electron density between the bacteria (arrowhead) and/or electron-dense regions (arrow). c Membraneengulfed compartments containing bacteria surrounded by a single membrane (arrowhead) with an electron-transparent zone (asterisk), without any cytoplasmic material. d Cytoplasmic bacteria not enclosed by a membrane, indicated by a white asterisk. e Membrane-engulfed $\mathbf{h}$

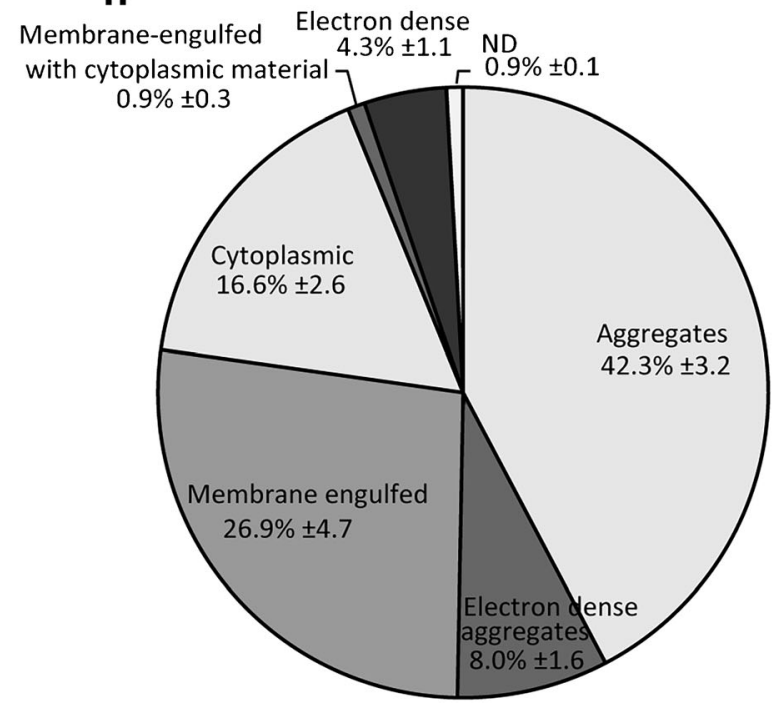

compartments with cytoplasmic material containing bacteria (asterisk), and partially degraded content (arrowhead) and other fused vacuoles (arrows). f Electron-dense compartments containing bacteria (asterisk) with uniform electron-dense content (arrow). g,h The fractions ( \pm SEM) of intracellular $\mathrm{Mm}$ found in different compartments or free in the cytoplasm is presented in a pie chart for $m y d 88^{+/+}$(total is 2178 bacteria) (g) and $m y d 88^{-/-}$(total is 1655 bacteria) (h). $\mathrm{N}$ is 3 larvae with initial stage granulomas per group at $4 \mathrm{dpi}$, with the section at middle of granuloma were imaged and analysed for each larva. The scale bars in (a)-(b) $(2 \mu \mathrm{m})$ and in (c)-(f) $(500 \mathrm{~nm})$ 
can phagocytose bacterial aggregates and the acidification of phagosomes upon lysosomal fusion.

The number of leukocytes at the site of infection was significantly lower in the Myd88-deficient larvae. This lower number of leukocytes at the site of infection at 4 dpi was associated with a significantly lower number of TUNELpositive cells at this time point. This suggests that the lower number of leukocytes at the site of infection is due to reduced recruitment of these cells in $m y d 88^{-/-}$larvae rather than to an increased level of cell death. However, alternative explanations are possible, such as alterations in haematopoiesis that may be Myd88-dependent, or death of immune cells cell taking place outside the site of infection or at earlier stages. On the other hand, since our infection model only induces a very localized infection at the tailfin of larvae, only a relatively small number of leukocytes interact with the pathogens, which makes systemic effects unlikely. In addition, the total number of leukocytes has been shown to be similar in Myd88deficient and wild-type larvae at 3 and $5 \mathrm{dpf}[28,36]$, so it seems most likely that the lower number of immune cell at the site of infection results from a reduced recruitment of leukocytes in the myd 88 mutant larvae.

In recent studies, a direct link has been demonstrated between reduced macrophage recruitment and increased susceptibility to $\mathrm{Mm}$ infection using zebrafish with genetic or pharmacologically induced macrophage deficiencies. The reduced migration of macrophages in these models results in an impaired supply of macrophages, so apoptotic macrophages in the granuloma are not engulfed by recruited cells. This causes secondary necrosis, breakdown of these granuloma and consequently spread of bacteria and accelerated extracellular growth [37-39].

However, at an early stage of infection (3 hpi), it has been shown that the recruitment of leukocytes towards an $\mathrm{Mm}$ infection site is not dependent on Myd88-mediated signalling [40]. Apparently, there is a difference in Myd88 dependency between initial and long-term leukocyte response to $\mathrm{Mm}$ infection. The long-term recruitment is likely to be dependent on pro-inflammatory mediators including cytokines and leukotrienes and tissue remodelling factors like matrix metalloproteinases, and the genes encoding these factors are strongly induced during the formation of granulomas in zebrafish larvae [28]. This induction has been shown to be dependent on Myd88 signalling [28], which may explain the lower number of leukocytes at the infected site in $m y d 88^{-/}$larvae observed in the present study. Interestingly, the ratio between the number of dead cells and leukocytes present at the site of infection is higher in the mutant larvae, suggesting a higher percentage of cell death in recruited leukocytes. This may be a result of a higher bacterial load in the mutant larvae, since earlier observations have indicated that the lifespan of leukocytes is negatively correlated with the $M m$ load [24].

Using electron microscopy, we showed that the majority of bacteria in Myd88-deficient larvae were located extracellularly, most likely as a result of the reduced number of phagocytes present at the site of infection. The increased extracellular growth of $\mathrm{Mm}$ in $m y d 88^{-/-}$larvae found in this study is consistent with results obtained using comparable immunecompromised zebrafish models, using knockdown of the TNF and LTA4H expression [41]. In addition, the myd88 mutant larvae showed more compacted aggregations of $\mathrm{Mm}$ at the site of infection than the wild types.

Performing ultrastructural analysis using TEM enabled us to quantitatively study the intracellular bacteria that resided in the immune cells of the mutant and the wild type. In previous studies, we showed that the largest fraction of intracellular $\mathrm{Mm}$ in wild-type larvae were observed as electron-dense aggregates [31], which are a result of efferocytosis [24]. Efferocytosis, which is defined as reuptake of cell debris and bacterial content by phagocytes upon death of an infected cell, is a crucial innate immune response in the defence against mycobacterial infection [42]. Interestingly, in the present study, we show that in mutant larvae, only a slight very small fraction was found as electron-dense aggregates and a larger fraction as aggregates without electron-dense content. We therefore conclude that the presence of electron-dense content, representing acidification of these compartments containing larger aggregates, resulting from fusion of the compartment with a lysosome, is highly Myd88-dependent. Restriction of bacterial burden is highly dependent upon acidification of $\mathrm{Mm}$ containing compartments [43], so the deficiency in this process most likely contributes to the increased bacterial growth in $m y d 88^{-/-}$larvae. Previously, we showed that DNA damageregulated autophagy modulator 1 (Dram1) plays an important role in the lysosomal acidification of bacteria-containing compartments [27]. It was also shown in this study that the induction of dram1 expression upon Mm infection is Myd88-dependent. Therefore, we suggest that the reduced acidification of bacteria-containing compartments in the myd 88 mutant could be at least partly due to a compromised Myd88-Dram1 signalling pathway.

In summary, we have used a combination of light and electron microscopy applied to the tail fin $\mathrm{Mm}$ infection model in zebrafish larvae. We show that the inflammatory responses mediated by Myd 88 affect the number of leukocytes present at the site of infection as well as the acidification of intracellular compartments. As a result, deficiency in Myd88dependent signalling leads to an increased infection due to uncontrolled, mainly extracellular, mycobacterial growth.

Acknowledgements We thank Davy de Witt and Ulrike Nehrdich for their assistance with fish care and Michiel van der Vaart for the helpful discussion. 
Authors' contributions MS and HS designed the study and all experimental work was conducted by RH and GL. EB and AK assisted with TEM image acquisition and processing. RH and MS analysed and interpreted the data. RH and MS drafted a first version of the manuscript, and AM, PH and HS edited the manuscript. RH, GL, EB, PH, AK, AM, HS and MS approved the final version.

Funding Infectious disease research in our laboratory was supported by the European Union Seventh Framework Programme project ZFHEALTH (grant number HEALTH-F4-2010-242048) and the Cyttron II Program (LSH framework number FES0908).

Data availability Data will be provided on request.

Code Availability Not applicable.

\section{Declarations}

Conflict of interest The authors declare that they have no conflict of interest.

Ethics approval Zebrafish were handled in compliance with the local animal welfare regulations and maintained according to standard protocols (www.zfin.org).

\section{Consent to participate Not applicable.}

\section{Consent for publication Not applicable.}

Open Access This article is licensed under a Creative Commons Attribution 4.0 International License, which permits use, sharing, adaptation, distribution and reproduction in any medium or format, as long as you give appropriate credit to the original author(s) and the source, provide a link to the Creative Commons licence, and indicate if changes were made. The images or other third party material in this article are included in the article's Creative Commons licence, unless indicated otherwise in a credit line to the material. If material is not included in the article's Creative Commons licence and your intended use is not permitted by statutory regulation or exceeds the permitted use, you will need to obtain permission directly from the copyright holder. To view a copy of this licence, visit http://creativecommons.org/licenses/by/4.0/.

\section{References}

1. World Health Organization (2019) Global tuberculosis report 2019. https://www.who.int/tb/publications/global report/en/ Accessed 08 May 2020

2. Koul A, Arnoult E, Lounis N, Guillemont J, Andries K (2011) The challenge of new drug discovery for tuberculosis. Nature 469(7331):483-490. https://doi.org/10.1038/nature09657

3. Goldberg DE, Siliciano RF, Jacobs WR Jr (2012) Outwitting evolution: fighting drug-resistant TB, malaria, and HIV. Cell 148(6): 1271-1283. https://doi.org/10.1016/j.cell.2012.02.021

4. Armstrong JA, Hart PD (1971) Response of cultured macrophages to Mycobacterium tuberculosis, with observations on fusion of lysosomes with phagosomes. J Exp Med 134(3 Pt 1):713-740. https://doi.org/10.1084/jem.134.3.713

5. Russell DG (2007) Who puts the tubercle in tuberculosis? Nat Rev Microbiol 5(1):39-47. https://doi.org/10.1038/nrmicro1538
6. Simeone R, Sayes F, Song O, Groschel MI, Brodin P, Brosch R, Majlessi L (2015) Cytosolic access of Mycobacterium tuberculosis: critical impact of phagosomal acidification control and demonstration of occurrence in vivo. PLoS Pathog 11(2):e1004650. https:// doi.org/10.1371/journal.ppat.1004650

7. van der Wel N, Hava D, Houben D, Fluitsma D, van Zon M, Pierson J, Brenner M, Peters PJ (2007) M. tuberculosis and M. leprae translocate from the phagolysosome to the cytosol in myeloid cells. Cell 129(7):1287-1298. https://doi.org/10.1016/j.cell. 2007.05.059

8. Russell DG, Barry CE 3rd, Flynn JL (2010) Tuberculosis: what we don't know can, and does, hurt us. Science 328(5980):852-856. https://doi.org/10.1126/science.1184784

9. Vergne I, Fratti RA, Hill PJ, Chua J, Belisle J, Deretic V (2004) Mycobacterium tuberculosis phagosome maturation arrest: mycobacterial phosphatidylinositol analog phosphatidylinositol mannoside stimulates early endosomal fusion. Mol Biol Cell 15(2):751-760. https://doi.org/10.1091/mbc.e03-05-0307

10. Gengenbacher M, Kaufmann SH (2012) Mycobacterium tuberculosis: success through dormancy. FEMS Microbiol Rev 36(3):514532. https://doi.org/10.1111/j.1574-6976.2012.00331.x

11. Medzhitov R, Janeway C Jr (2000) The Toll receptor family and microbial recognition. Trends Microbiol 8(10):452-456. https:// doi.org/10.1016/s0966-842x(00)01845-x

12. Matzinger $P$ (2002) The danger model: a renewed sense of self. Science 296(5566):301-305. https://doi.org/10.1126/science. 1071059

13. Takeda K, Akira S (2004) Microbial recognition by Toll-like receptors. J Dermatol Sci 34(2):73-82. https://doi.org/10.1016/j. jdermsci.2003.10.002

14. Gay NJ, Gangloff M, O'Neill LA (2011) What the Myddosome structure tells us about the initiation of innate immunity. Trends Immunol 32(3):104-109. https://doi.org/10.1016/j.it.2010.12.005

15. Lin SC, Lo YC, Wu H (2010) Helical assembly in the MyD88IRAK4-IRAK2 complex in TLR/IL-1R signalling. Nature 465(7300):885-890. https://doi.org/10.1038/nature09121

16. Muzio M, Ni J, Feng P, Dixit VM (1997) IRAK (Pelle) family member IRAK-2 and MyD88 as proximal mediators of IL-1 signaling. Science 278(5343):1612-1615. https://doi.org/10.1126/ science.278.5343.1612

17. Wesche H, Korherr C, Kracht M, Falk W, Resch K, Martin MU (1997) The interleukin-1 receptor accessory protein (IL-1RAcP) is essential for IL-1-induced activation of interleukin-1 receptor-associated kinase (IRAK) and stress-activated protein kinases (SAP kinases). J Biol Chem 272(12):7727-7731. https://doi.org/10. 1074/jbc.272.12.7727

18. Ryffel B, Fremond C, Jacobs M, Parida S, Botha T, Schnyder B, Quesniaux V (2005) Innate immunity to mycobacterial infection in mice: critical role for toll-like receptors. Tuberculosis (Edinb) 85(56):395-405. https://doi.org/10.1016/j.tube.2005.08.021

19. Ramakrishnan L (2013) Looking within the zebrafish to understand the tuberculous granuloma. Adv Exp Med Biol 783:251-266. https://doi.org/10.1007/978-1-4614-6111-1_13

20. Swaim LE, Connolly LE, Volkman HE, Humbert O, Born DE, Ramakrishnan L (2006) Mycobacterium marinum infection of adult zebrafish causes caseating granulomatous tuberculosis and is moderated by adaptive immunity. Infect Immun 74(11):6108-6117. https://doi.org/10.1128/IAI.00887-06

21. Cronan MR, Tobin DM (2014) Fit for consumption: zebrafish as a model for tuberculosis. Dis Model Mech 7(7):777-784. https://doi. org $110.1242 / \mathrm{dmm} .016089$

22. Davis JM, Clay H, Lewis JL, Ghori N, Herbomel P, Ramakrishnan L (2002) Real-time visualization of mycobacterium-macrophage interactions leading to initiation of granuloma formation in zebrafish embryos. Immunity 17(6):693-702. https://doi.org/10. 1016/s1074-7613(02)00475-2 
23. Meijer AH (2016) Protection and pathology in TB: learning from the zebrafish model. Semin Immunopathol 38(2):261-273. https:// doi.org/10.1007/s00281-015-0522-4

24. Hosseini R, Lamers GE, Soltani HM, Meijer AH, Spaink HP, Schaaf MJ (2016) Efferocytosis and extrusion of leukocytes determine the progression of early mycobacterial pathogenesis. J Cell Sci 129(18):3385-3395. https://doi.org/10.1242/jcs.135194

25. Davis JM, Ramakrishnan L (2009) The role of the granuloma in expansion and dissemination of early tuberculous infection. Cell 136(1):37-49. https://doi.org/10.1016/j.cell.2008.11.014

26. Elks PM, van der Vaart M, van Hensbergen V, Schutz E, Redd MJ, Murayama E, Spaink HP, Meijer AH (2014) Mycobacteria counteract a TLR-mediated nitrosative defense mechanism in a zebrafish infection model. PLoS One 9(6):e100928. https://doi.org/10.1371/ journal.pone. 0100928

27. van der Vaart M, Korbee CJ, Lamers GE, Tengeler AC, Hosseini R, Haks MC, Ottenhoff TH, Spaink HP, Meijer AH (2014) The DNA damage-regulated autophagy modulator DRAM1 links mycobacterial recognition via TLR-MYD88 to autophagic defense [corrected]. Cell Host Microbe 15(6):753-767. https://doi.org/10. 1016/j.chom.2014.05.005

28. van der Vaart M, van Soest JJ, Spaink HP, Meijer AH (2013) Functional analysis of a zebrafish myd88 mutant identifies key transcriptional components of the innate immune system. Dis Model Mech 6(3):841-854. https://doi.org/10.1242/dmm.010843

29. Rougeot J, Torraca V, Zakrzewska A, Kanwal Z, Jansen HJ, Sommer F, Spaink HP, Meijer AH (2019) RNAseq profiling of leukocyte populations in zebrafish larvae reveals a cxcl11 chemokine gene as a marker of macrophage polarization during mycobacterial infection. Front Immunol 10:832. https://doi.org/10.3389/ fimmu.2019.00832

30. Roca FJ, Ramakrishnan L (2013) TNF dually mediates resistance and susceptibility to mycobacteria via mitochondrial reactive oxygen species. Cell 153(3):521-534. https://doi.org/10.1016/j.cell. 2013.03.022

31. Hosseini R, Lamers GE, Hodzic Z, Meijer AH, Schaaf MJ, Spaink HP (2014) Correlative light and electron microscopy imaging of autophagy in a zebrafish infection model. Autophagy 10(10): 1844-1857. https://doi.org/10.4161/auto.29992

32. Benard EL, van der Sar AM, Ellett F, Lieschke GJ, Spaink HP, Meijer AH (2012) Infection of zebrafish embryos with intracellular bacterial pathogens. J Vis Exp 61. https://doi.org/10.3791/3781

33. Loynes CA, Martin JS, Robertson A, Trushell DM, Ingham PW, Whyte MK, Renshaw SA (2010) Pivotal advance: pharmacological manipulation of inflammation resolution during spontaneously resolving tissue neutrophilia in the zebrafish. J Leukoc Biol 87(2): 203-212. https://doi.org/10.1189/jlb.0409255

34. Schindelin J, Arganda-Carreras I, Frise E, Kaynig V, Longair M, Pietzsch T, Preibisch S, Rueden C, Saalfeld S, Schmid B, Tinevez
JY, White DJ, Hartenstein V, Eliceiri K, Tomancak P, Cardona A (2012) Fiji: an open-source platform for biological-image analysis. Nat Methods 9(7):676-682. https://doi.org/10.1038/nmeth.2019

35. Faas FG, Avramut MC, van den Berg BM, Mommaas AM, Koster AJ, Ravelli RB (2012) Virtual nanoscopy: generation of ultra-large high resolution electron microscopy maps. J Cell Biol 198(3):457469. https://doi.org/10.1083/jcb.201201140

36. Koch BEV, Yang S, Lamers G, Stougaard J, Spaink HP (2018) Intestinal microbiome adjusts the innate immune setpoint during colonization through negative regulation of MyD88. Nat Commun 9:4099. https://doi.org/10.1038/s41467-018-06658-4

37. Berg RD, Levitte S, O'Sullivan MP, O'Leary SM, Cambier CJ, Cameron J, Takaki KK, Moens CB, Tobin DM, Keane J, Ramakrishnan L (2016) Lysosomal disorders drive susceptibility to tuberculosis by compromising macrophage migration. Cell 165(1):139-152. https://doi.org/10.1016/j.cell.2016.02.034

38. Meijer AH, Aerts JM (2016) Linking smokers' susceptibility to tuberculosis with lysosomal storage disorders. Dev Cell 37(2): 112-113. https://doi.org/10.1016/j.devcel.2016.04.004

39. Pagan AJ, Yang CT, Cameron J, Swaim LE, Ellett F, Lieschke GJ, Ramakrishnan L (2015) Myeloid growth factors promote resistance to mycobacterial infection by curtailing granuloma necrosis through macrophage replenishment. Cell Host Microbe 18(1):15-26. https://doi.org/10.1016/j.chom.2015.06.008

40. Cambier CJ, Takaki KK, Larson RP, Hernandez RE, Tobin DM, Urdahl KB, Cosma CL, Ramakrishnan L (2014) Mycobacteria manipulate macrophage recruitment through coordinated use of membrane lipids. Nature 505(7482):218-222. https://doi.org/10.1038/ nature 12799

41. Tobin DM, Roca FJ, Oh SF, McFarland R, Vickery TW, Ray JP, Ko DC, Zou Y, Bang ND, Chau TT, Vary JC, Hawn TR, Dunstan SJ, Farrar JJ, Thwaites GE, King MC, Serhan CN, Ramakrishnan L (2012) Host genotype-specific therapies can optimize the inflammatory response to mycobacterial infections. Cell 148(3):434-446. https://doi.org/10.1016/j.cell.2011.12.023

42. Martin CJ, Booty MG, Rosebrock TR, Nunes-Alves C, Desjardins DM, Keren I, Fortune SM, Remold HG, Behar SM (2012) Efferocytosis is an innate antibacterial mechanism. Cell Host Microbe 12(3):289-300. https://doi.org/10.1016/j.chom.2012.06. 010

43. Levitte S, Adams KN, Berg RD, Cosma CL, Urdahl KB, Ramakrishnan L (2016) Mycobacterial acid tolerance enables phagolysosomal survival and establishment of tuberculous infection in vivo. Cell Host Microbe 20(2):250-258. https://doi.org/10. 1016/j.chom.2016.07.007

Publisher's note Springer Nature remains neutral with regard to jurisdictional claims in published maps and institutional affiliations. 